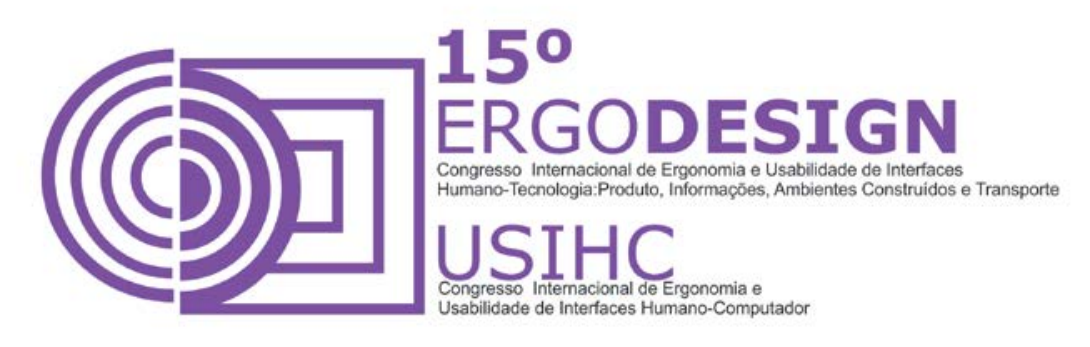

\title{
AVALIAÇÃO ERGONÔMICA DO AMBIENTE CONSTRUIDO: ESTUDO DE CASO NO ARQUIVO FUNCIONAL DE UMA INSTITUIÇÃO PÚBLICA DE ENSINO SUPERIOR
}

\section{ERGONOMIC EVALUATION OF BUILT ENVIRONMENT: CASE STUDY IN A FUNCTIONAL FILE PUBLIC INSTITUTION FO EDUCATION HIGHER}

\author{
SILVA, Ana Cláudia Colaço Lira (1); \\ SILVA, Aline Nascimento (2); \\ SILVA, Valéria C. Pereira da Rocha (3); \\ RAMOS, Maria Lúcia Silva (4); \\ VILLAROUCO, Vilma (5).
}

(1) Universidade Federal de Pernambuco, Mestranda em Ergonomia e-mail: claudiaclira@gmail.com

(2) Universidade Federal de Pernambuco, Mestranda em Ergonomia e-mail: alineufpe@yahoo.com.br

(3) Universidade Federal de Pernambuco, Mestranda em Ergonomia e-mail: valeria628@gmail.com

(4) Universidade Federal de Pernambuco, Mestranda em Ergonomia e-mail: mluciaramos2001@gmail.com

(5) Universidade Federal de Pernambuco, Pós-doutora em Engenharia e-mail: villarouco@hotmail.com

\section{RESUMO}

Este artigo relata uma avaliação ergonômica do ambiente construído realizada em um arquivo funcional de uma instituição Pública de Ensino Superior situada na Cidade do Recife, PE. Buscou-se identificar as expectativas e impressões dos seus usuários e avaliar se este espaço atende às suas necessidades. Para tanto, aplicou-se a Metodologia Ergonômica para o Ambiente Construído (MEAC), proposta por Villarouco (2008). A partir da análise dos dados, foi possível identificar alguns problemas nos espaços e recomendações prováveis foram sugeridos. 


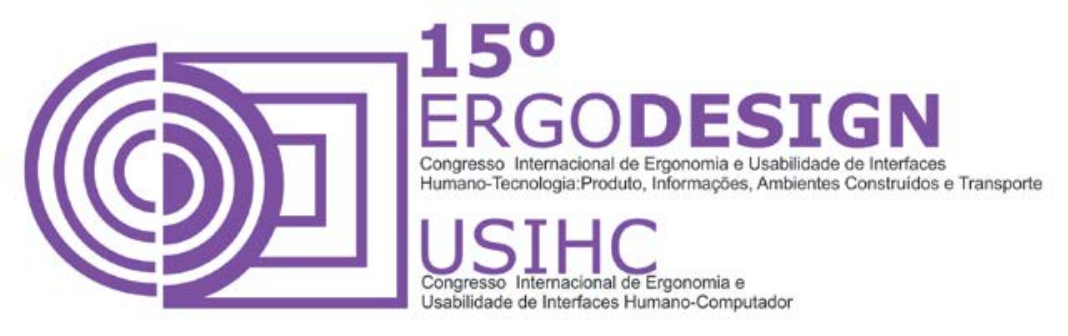

Palavras-chave: Ergonomia; Ambiente construído; Arquivo funcional.

\section{ABSTRACT}

This paper reports an ergonomic evaluation of the environment built held in a functional file a public institution of higher education located in Recife, PE. We tried to identify the expectations and impressions of their users and assess whether this space suits your needs. Therefore, we applied the Ergonomic Methodology for the Built Environment (MEAC), proposed by Villarouco (2008). From the data analysis, it was possible to identify some problems in the spaces and probable recommendations were suggested.

Keywords: Ergonomics; Built Environment; Functional File.

\section{INTRODUÇÃO}

Atualmente, tornar um ambiente de trabalho mais harmonioso e produtivo é um dos grandes desafios enfrentados por empresas, sejam elas públicas ou privadas. Nesta perspectiva, evocamos a ergonomia, tendo em vista que a mesma preconiza a adaptação do trabalho ao homem. Mont Alvão (2011) chama a atenção para o fato de que "o usuário e o espaço em que nele ocupa, interagem, sendo necessário avaliar como se dá esta interação".

No contexto, o ambiente escolhido para o desenvolvimento da pesquisa foi o Arquivo Funcional de uma Instituição de Ensino Superior Pública Federal, localizada em Recife/PE. A Associação de Arquivistas Brasileiros (2014) adota a seguinte definição: "Arquivo é o conjunto de documentos que, independentemente da natureza ou do suporte, são reunidos por acumulação ao longo das atividades de pessoas físicas ou jurídicas, públicas ou privadas". O cenário atual apresenta um equívoco nas administrações no tocante ao assunto em questão, pois quando se fala em arquivamento, facilmente pensa-se em um móvel de aço inflexível instalado em áreas menos nobres e de difícil acesso. Por outro lado, quando existe uma preocupação adequada em gerenciar a documentação produzida em uma Instituição, o arquivo passa a exercer um importante papel. Para isso, alertamos que os gestores devem se conscientizar de que o investimento em soluções para o gerenciamento de documentos resulta em agilidade e competitividade. Um arquivo desorganizado prejudica a velocidade das atividades, a pesquisa e a tomada de decisões, resulta em maior ocupação de espaço físico, aumenta o risco de perda de informação, além de inviabilizar o acesso ao conhecimento da empresa e atingindo diretamente a vida funcional de seus servidores.

Assim, este artigo tem como objetivo geral apresentar uma avaliação ergonômica em um Arquivo Funcional de uma Instituição de Ensino Superior Pública Federal, identificando possíveis problemas existentes no espaço (relacionados ao dimensionamento do ambiente físico, confortos térmico, lumínico e acústico, fluxos, leiaute, acessibilidade e demais condicionantes), e relacioná-los com a percepção dos profissionais lotados no setor. 


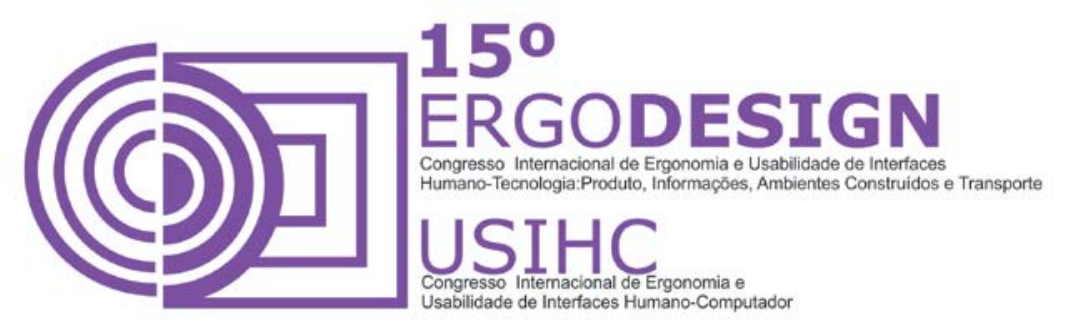

\section{METODOLOGIA}

Esta pesquisa caracteriza-se como descritiva, tendo em vista que analisou e registrou fatos ou fenômenos sem manipulá-los, de acordo com o pensamento de CERVO, BERVIAN E SILVA (2007). Neste estudo, utilizamos a Metodologia do Ambiente Construído (MEAC), proposta por VILLAROUCO (2008), visando compreender não apenas os aspetos físicos e o conforto ambiente, mas principalmente a percepção que os usuários têm sobre o espaço. A seguir, apresentamos as etapas, métodos e procedimentos adotados nesta pesquisa:

Etapa 01 - Análise Global do Ambiente: Realizamos uma pesquisa de campo, através de observações assistemáticas e registro fotográfico do ambiente, além de entrevista com usuários do setor. Preconiza-se neste momento, a existência de problemas latentes no ambiente.

Etapa 02 - Identificação da Configuração Ambiental: Levantamos e registramos as informações referentes ao Arquivo Funcional de Instituição de Ensino Superior Pública Federal. Para a avaliação das condições locais, observou-se o ambiente físico dos postos de trabalho, as condições ambientais (ruído, temperatura, iluminação), além das questões de acessibilidade e segurança e por fim realizamos as medições dos índices ambientais descritos. As medidas padrão foram obtidas através da legislação existentes para aos aspectos analisados e serão explicitadas no desenvolvimento desta etapa. As medições foram realizadas pelas pesquisadoras nos horários da manhã e tarde buscando evidenciar os períodos de maior movimentação no Setor.

Etapa 03 - Avaliação do Ambiente em Uso: Foram observadas, nesta etapa, as diversas atividades desenvolvidas em uma Instituição de Ensino Superior Público Federal, ao qual o ambiente está inserido, além do atendimento ao público; e registrados os seus fluxos mediante fluxogramas e fotografias.

Etapa 04 - Percepção Ambiental do Usuário: Buscou-se investigar as impressões e expectativas dos usuários em relação ao seu espaço de trabalho. A ferramenta utilizada para alcançar tal objetivo foi a Constelação de Atributos, amplamente aplicada nas pesquisas de Villarouco. A amostra foi intencional coletada com a concordância e o esclarecimento de todos a respeito da pesquisa em questão. Participaram 20 servidores/estagiários do setor, correspondendo a $67 \%$ do universo da pesquisa que corresponde a 30 usuários, em que responderam as seguintes perguntas: 01) Quando você pensa em um "Arquivo Funcional" que ideias ou imagens vem à mente?; 02) Quando você pensa neste "Arquivo Funcional" que ideias ou imagens vem à mente? Para registro e posterior sistematização e construção do mapa, as respostas foram amplamente analisadas pelas pesquisadoras e, posteriormente tabuladas.

Etapa 05 - Diagnóstico Ergonômico do Ambiente: Após as análises dos dados e dos registros efetuados durante o estudo, além das impressões captadas dos usuários, foram feitas considerações sobre o ambiente e as atividades praticadas no local. 


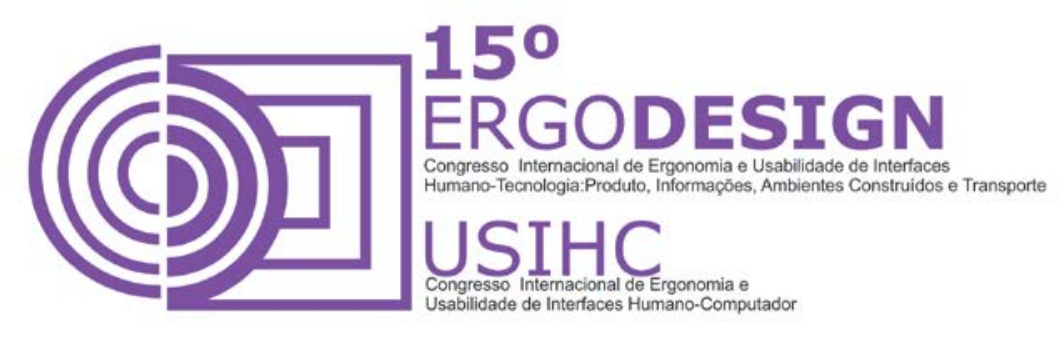

\section{ANÁLISE ERGONÔMICA}

\subsection{Etapa 01 - Análise Global do Ambiente}

Trata-se de uma Repartição Pública Federal, situada no Prédio da Administração Central, domiciliada na Avenida Professor Moraes Rêgo, 1235 - na Cidade Universitária, CEP 50.670.901, Recife. Possui em seu quadro funcional 18(dezoito) servidores efetivos e 12 (doze) estagiários (alunos graduandos dos diversos curso oferecidos pela Instituição), perfazendo um total de 30 servidores. Consta em seu organograma um gestor de pessoal, uma diretora e uma chefe de seção. Funciona no horário das 7:30 às 12:30 e das 14:00 às 17:00 horas de segunda a sexta-feira. A Divisão conta com diversos postos de trabalho, 02 bancadas pequenas e uma bancada extensa. Os banheiros (feminino e masculino) e a copa localizam-se em uma área externa à divisão, de uso compartilhado com as demais Divisões. A atividade fim da seção é a guarda da documentação produzida pelos servidores da Instituição de Ensino Superior, sendo considerado um trabalho diversificado que atende aos três campi e Órgãos Suplementares da IES (Instituição de Ensino Superior). Vale ressaltar que não se arquiva nesta divisão/SRF, documentos dos discentes da Instituição. Então, a SRF, trata de receber processos de toda tipologia entre os quais: portarias, ofícios, requerimentos, férias, licenças (prêmio, sem vencimento, doença e maternidade, etc.), dentre outros documentos, sempre referentes aos servidores, sejam eles ativos, aposentados, docentes, docentes substitutos, visitantes, temporários e falecidos. As documentações são recepcionadas, por um guichê improvisado em uma abertura na porta da sala. Os estagiários se revezam no atendimento e registro das demandas e documentações junto ao programa de computador utilizado pela IES (Instituição de Ensino Superior) para registro e acompanhamento das demandas de acordo com a numeração atribuída a cada uma delas no momento do seu protocolo. Diversos equipamentos e mobiliários compõem o local: Mobiliários (birôs, bancadas cumpridas, cadeiras, armários pequenos e médios, além da ESTANTE MODULAR); Acesso à Internet e Wireless; Um equipamento que faz a higienização dos documentos com visível carência de espaço para se instalar uma bancada específica para preparar a documentação, de acordo com informações prestadas pelos servidores. Observou-se que, apesar do ambiente interno possuí uma janela em toda extensão da parede, a iluminação artificial é influenciada pela iluminação natural, uma vez que, segundo relato dos servidores, as persianas existentes, geralmente permanecem abertas. Há dois extintores contra incêndio no chão, cercados por caixas de arquivo e pastas. Existe apenas um extintor fixado na parede do corredor do Arquivo. Algumas características físicas do local foram evidenciadas: Área de circulação interna é inadequada, sobretudo do corredor de ligação; Iluminação e Ventilação artificiais; Janelas com persianas, grades e aparelhos de arcondicionado.

Quanto ao mobiliário, é possível observar que em todas as bancadas existentes há um acúmulo excessivo de documentos que dificultam o próprio desenvolvimento das atividades e também o posicionamento adequado das cadeiras. O acesso constante ao Arquivo modular é comprometido, pois em diversas ocasiões, faz-se necessário o uso de uma pequena escada para alcançar as prateleiras mais altas. Por outro lado, há momentos em que o trabalhador precisa parar sua atividade para que o outro consiga realizar a sua. A limpeza neste ambiente 


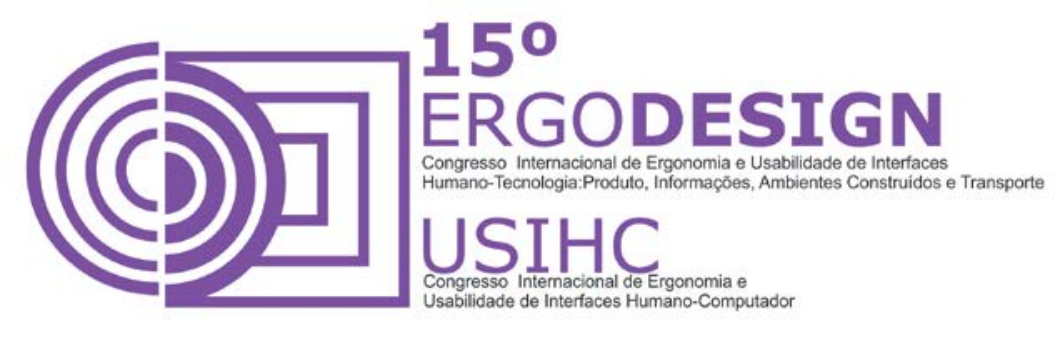

ocorre de forma precária pela falta de espaço e também pelo receio apresentado pela equipe que realiza este serviço em perder e ou descartar algum documento importante.

\subsection{Etapa 02 - Identificação da Configuração Ambiental}

A etapa de conforto ambiental é fundamental para identificar se as condições oferecidas pelo ambiente atendem as suas respectivas Normas Técnicas. A unidade possui duas portas de acesso, entretanto, utiliza-se apenas uma, pela qual é realizado também o atendimento ao público em geral. Notou-se ainda uma quantidade excessiva de arquivos e pastas em cima nos birôs e bancadas e abaixo destes, gerando uma impressão de local inadequado para a realização das tarefas. As figuras a seguir mostram detalhes do ambiente. A figura 01 evidencia a porta de acesso ao local, próxima ao birô, situada em um extenso corredor. A figura 02, 0 posto de trabalho após o acesso principal. As figuras 03 e 04 visualizam corredores internos da Estante Modular do arquivo. As figuras 05 e 06 exibem o corredor externo de ligação entre os postos de trabalho, no qual podemos constatar uma inadequação de espaço, para abrir as portas do Arquivo Modular, utilizar a bancada para análise de documentos e ainda para circulação geral no divisão. As alavancas para abertura das ruas da Estante Modular representam um potencial risco à saúde dos trabalhadores, sendo possível observar que ao abrir a porta de acesso, a mesa de trabalho fica prejudicada.

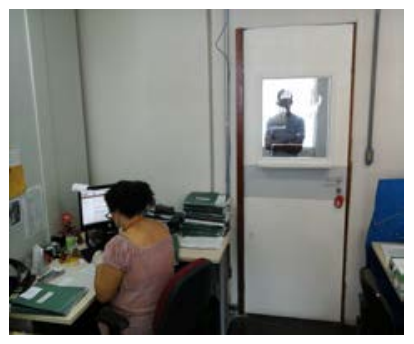

Fig. 01 - Guichê de atendimento

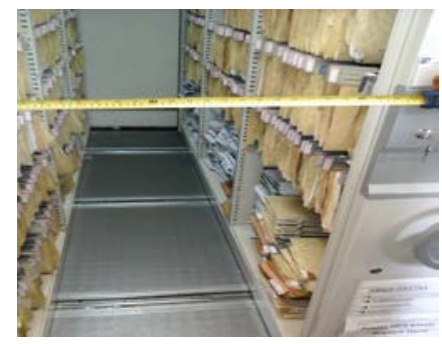

Fig. 04 - Corredor da Estante modular

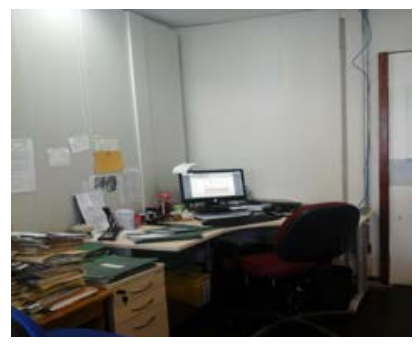

Fig. 02 - Posto de trabalho inicial

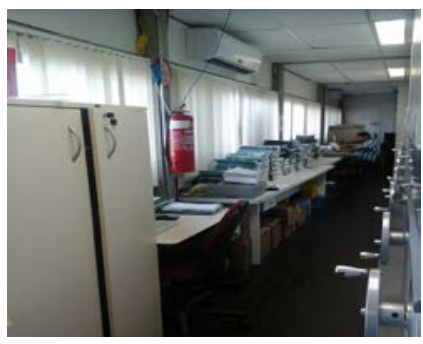

Fig. 05 - Corredor central da Seção

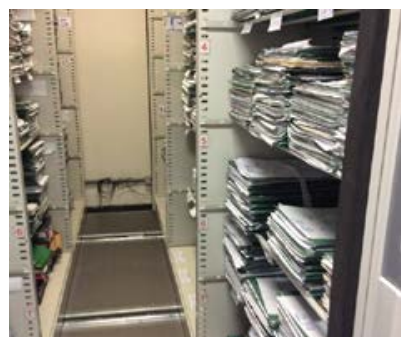

Fig. 03 - Corredor Estante modular

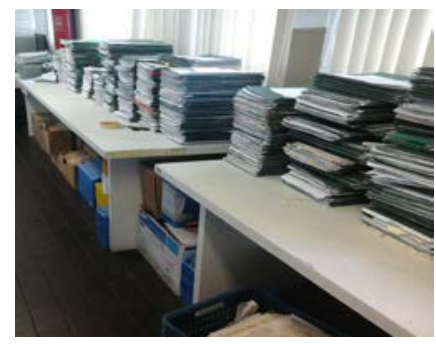

Fig. 06 - Bancadas Centrais

Fonte das imaqens: Arauivo das autoras

As medições foram obtidas durante os diversos horários de desempenho das atividades de trabalho. Os equipamentos utilizados para as medições apresentaram as seguintes especificações: $\quad$ Iluminância - Luxímetro digital marca Minipa, modelo MLM-101; Acústica - 


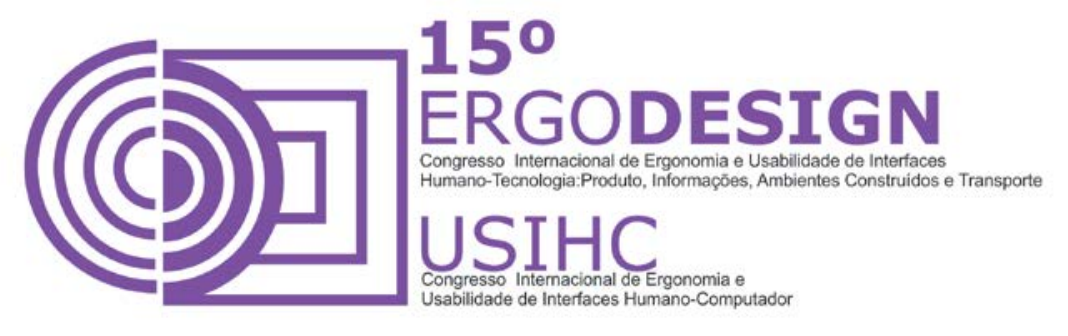

Sonômetro digital marca Minipa, modelo MSL-1325 e Temperatura e Umidade Relativa do Ar - Termo Higrômetro Digital, marca Minipa, modelo 7666.02.0.00. As Normas Técnicas vigentes que foram utilizadas como parâmetro de avaliação dos aspectos mencionados foram: NRB 5413 - que recomenda iluminação geral média para área de trabalho750 lux. A partir dos dados expostos na tabela 01 abaixo, observou-se que em apenas três pontos aferidos, aproximou-se ao mínimo indicado na legislação, e mesmo assim, percebemos que tais pontos sofreram a interferência direta da iluminação natural através da janela do ambiente; NR 17 - utilizada como parâmetro, recomenda o som de até 65 dB; embora a NRB 10.152 recomende que os sons nos ambientes em estudo oscilem entre 45 e $55 \mathrm{~dB}$. Deste modo, em relação aos índices de ruído, foram constados, de acordo com os dados apresentados na Tabela 02 que o setor atende a legislação.

Quadro 01: Dados para medição de CONFORTO LUMÍNICO (Fonte: autoras, 2014)

Quadro 02: Dados para medição de CONFORTO ACÚSTICO (Fonte: autoras, 2014)

\begin{tabular}{|c|c|c|c|c|c|}
\hline \multirow{2}{*}{ PONTO } & \multicolumn{3}{|c|}{ Ruido } & \multirow{2}{*}{ NR 17} & \multirow{2}{*}{ LOCAL } \\
\hline & $1^{\text {a) }}$ À partir das 9:15h & $2^{\mathrm{a})}$ À partir das $11: 10 \mathrm{~h}$ & $3^{\mathrm{a})}$ À partir das $14: 10 \mathrm{~h}$ & & \\
\hline 01 & 53,3 & 69,2 & 66,1 & \multirow{7}{*}{ Até $65 \mathrm{~dB}$} & Posto \\
\hline 02 & 52,2 & 54,7 & 58,7 & & Corredor do ARQ. \\
\hline 03 & 50,4 & 43,9 & 52,6 & & Interior A-B ARQ. \\
\hline 04 & 46,2 & 44,4 & 46,7 & & Interior I-J AARQ. \\
\hline 05 & 44,4 & 46,4 & 65,7 & & Interior S-T ARQ. \\
\hline 06 & 47,0 & 61,6 & 52,7 & & Posto \\
\hline 07 & 46,1 & 58,2 & 52,6 & & Bancada sala 193 \\
\hline
\end{tabular}

NR 17 sugere uma variância entre $20^{\circ} \mathrm{C}$ e $23^{\circ} \mathrm{C}$ graus centígrados. Quanto a temperatura, observou-se que o ambiente atende ao solicitado na legislação. Cumpre registrar entretanto, que a IES localiza-se no Recife/PE, região Nordeste que possui um clima tropical, justificando-se como aceitável as pequenas oscilações encontradas no ambiente. Nas questões da umidade relativa do ar encontradas no Setor demonstraram-se satisfatórias.

Quadro 03: Dados para medição de CONFORTO TÉRMICO (Fonte: autoras, 2014)

\begin{tabular}{|c|c|c|c|c|c|}
\hline \multirow[b]{2}{*}{ Ponto } & \multicolumn{3}{|c|}{ Temperatura e Umidade Relativa do AR } & \multirow{2}{*}{ NR 17} & \multirow{2}{*}{ LOCAL } \\
\hline & 1ª) Á partir 10:09h & 1ª) Á partir 12:42h & 1ª Á partir 16:C & & \\
\hline \multirow{2}{*}{ PONTO } & \multicolumn{3}{|c|}{ lluminância } & \multirow{2}{*}{ NBR 5.413} & \multirow{2}{*}{ LOCAL } \\
\hline & $1^{\text {a) }}$ À partir das $9: 15 \mathrm{~h}$ & $2^{\mathrm{a})}$ À partir das 11:10h & $3^{\mathrm{a})}$ À partir das 14:10h & & \\
\hline 01 & 26,1 & 27,9 & 272 & 300-500-750lux & Posto \\
\hline 02 & 47,1 & 140,1 & 82 & 300-500-750lux & Corredor do AUQ. \\
\hline 03 & 0,63 & 0,38 & 152 & 300-500-750lux & Interior A-B ARQ. \\
\hline 04 & 0,28 & 0,38 & 0,20 & 300-500-750lux & Interior I-J AARQ. \\
\hline 05 & 16,6 & 152 & 136 & 300-500-750lux & Interior S-T ARQ. \\
\hline 06 & 19,3 & 159 & 209 & 300-500-750lux & Posto \\
\hline 07 & 29,9 & 297 & 151 & 300-500-750lux & Bancada sala 193 \\
\hline
\end{tabular}




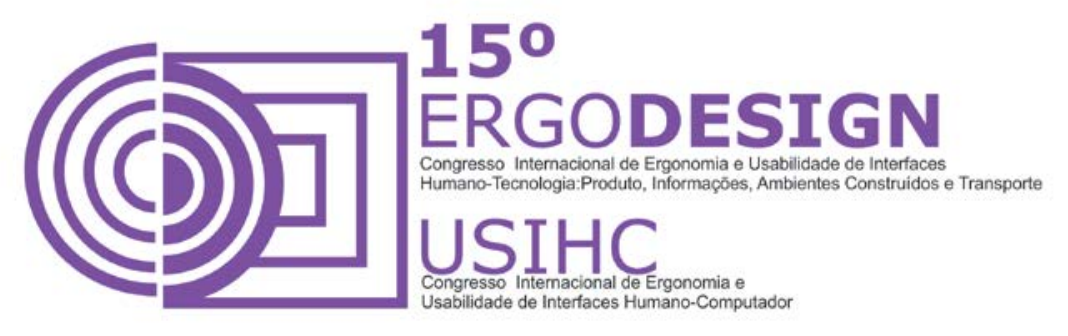

\begin{tabular}{|c|c|c|c|c|c|}
\hline 01 & $23,3^{\circ} \mathrm{C}-47 \%$ UR & $23,5^{\circ} \mathrm{C}-47 \%$ UR & $25,5^{\circ} \mathrm{C}-41 \%$ UR & \multirow{7}{*}{$\begin{array}{c}20-23^{\circ} \mathrm{C} \text { e } \\
\text { Umidade } \\
\text { Relativa do } \\
\text { Ar não } \\
\text { inferior a } \\
40 \%\end{array}$} & Posto \\
\hline 02 & $23,6^{\circ} \mathrm{C}-47 \%$ UR & $24,2^{\circ} \mathrm{C}-47 \%$ UR & $25,2^{\circ} \mathrm{C}-40 \%$ UR & & Corredor do ARQ. \\
\hline 03 & $24,8^{\circ} \mathrm{C}-47 \%$ UR & $23,8^{\circ} \mathrm{C}-45 \%$ UR & $25,1^{\circ} \mathrm{C}-41 \%$ UR & & Interior A-B ARQ. \\
\hline 04 & $23,8^{\circ} \mathrm{C}-47 \%$ UR & $23,5^{\circ} \mathrm{C}-45 \%$ UR & $25,0^{\circ} \mathrm{C}-40 \%$ UR & & Interior I-J AARQ. \\
\hline 05 & $23,8^{\circ} \mathrm{C}-47 \%$ UR & $23,3^{\circ} \mathrm{C}-46 \%$ UR & $25,4^{\circ} \mathrm{C}-40 \%$ UR & & Interior S-T ARQ. \\
\hline 06 & $24,8^{\circ} \mathrm{C}-46 \%$ UR & $24,8^{\circ} \mathrm{C}-47 \%$ UR & $25,2^{\circ} \mathrm{C}-40 \%$ UR & & Posto \\
\hline 07 & $24,8^{\circ} \mathrm{C}-46 \%$ UR & $24,8^{\circ} \mathrm{C}-44 \%$ UR & $23,4^{\circ} \mathrm{C}-40 \%$ UR & & Bancada sala 177 \\
\hline
\end{tabular}

\subsection{Acessibilidade}

A Norma Técnica vigente que foi utilizada como parâmetro de avaliação dos aspectos de Acessibilidade do ambiente em estudo foi a Norma da Associação Brasileira de Normas Técnicas NBR 9050 - Acessibilidade. Analisamos também alguns aspectos de segurança no local. O prédio da Reitoria da IES possui três pavimentos (Térreo, $1^{\circ}$ e $2^{\circ}$ andares), a divisão em análise neste trabalho situa-se no Térreo. A Figura 07 visualiza 0 acesso principal à Administração Central, onde percebemos que a calçada não apresenta o rebaixamento necessário para cadeirante, além de apresentar uma barreira física no centro da calçada. No pavimento térreo da Reitoria existe um elevador de acesso aos pavimentos superiores da edificação, em acordo a Norma NRB 9050 para a especificação da porta que mede $80 \mathrm{~cm}$, entretanto não possui aviso sonoro nem piso tátil, visualizado na Figura 08. As figuras 09 e 10 correspondem a segunda entrada (dos fundos) da Reitoria, na qual identificamos uma escadaria, uma rampa de acesso com corrimão e uma calçada, ambos atendem a especificação exigida na legislação em vigor. A Figura 11 mostra a disposição de dois extintores na parte interna da divisão, em total desacordo com as normas de segurança. A Figura 12 expõe um extintor localizado no Corredor externo de acesso a divisão, também em desacordo com as normas de segurança.

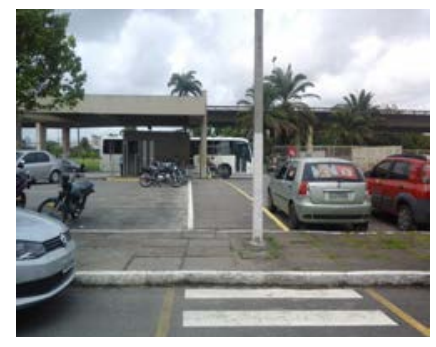

Fig. 07 - Acesso principal a Adm. Central da IES

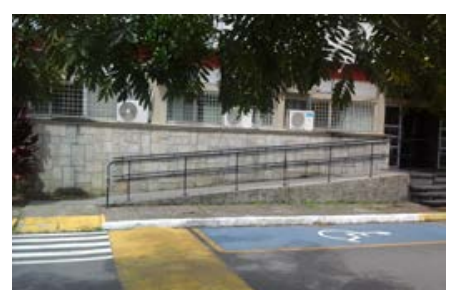

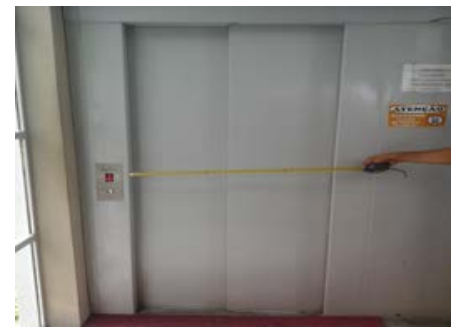

Fig. 08 - Elevador localizado no prédio da Adm. Central da IES

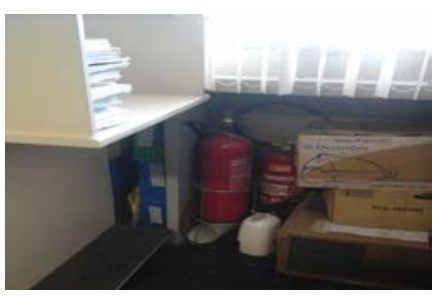

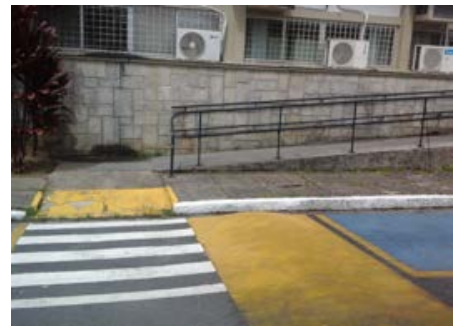

Fig. 09 - Rampa do $2^{\circ}$ Acesso ao prédio da Adm. Central da IES

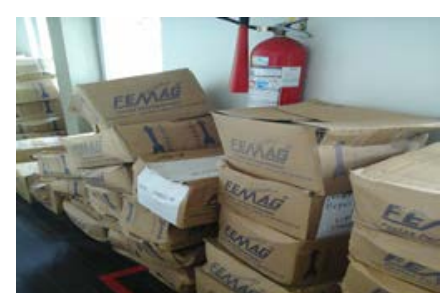




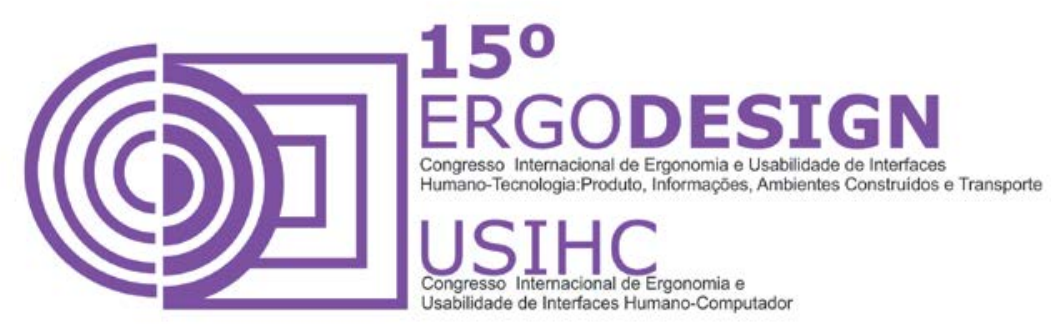

Fig. 10 - Rampa no segundo Acesso - Adm. Central da IES
Fig. 11 - Extintores embaixo da ianela na Seç̃o
Fig.12 - Caixas no corredor de acesso ao Setor

Fonte das imagens: Arquivo das autoras

\section{Etapa 04 - Avaliação do Ambiente em Uso no Desempenho das Atividades}

Nesta etapa, busca-se identificar o quanto facilitador ou inibidor o ambiente representa ao desenvolvimento das atividades que abriga. Os fluxos de acesso para os cadeirantes classificados na cor verde indicam boa circulação; na cor amarela representam alerta e na cor vermelha evidencia um péssimo indicador para único acesso a esse público à Divisão. Desde modo, evidenciamos que a atual configuração inviabiliza o acesso quando há alguma demanda para atendimento a esse público específico, fazendo-se necessário haver o deslocamento do servidor para realizar o atendimento. Nas Figuras 13 e 14, podemos visualizar a qualidade dos Fluxos de Circulação para Cadeirante, bem como o Fluxo de Circulação Geral.

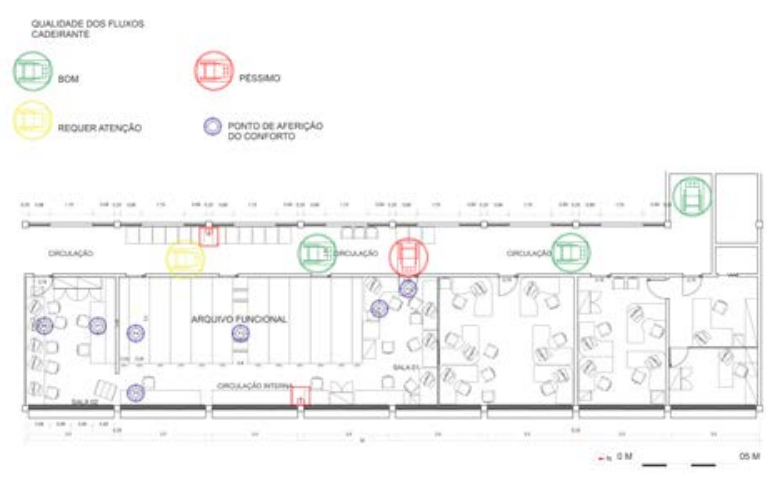

Figura 13 - Planta Baixa

Fluxo de Circulação Cadeirante (Fonte: autoras, 2014)

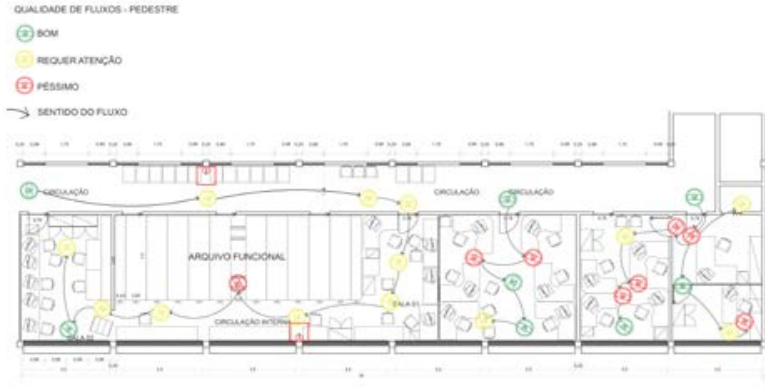

Figura 14 - Planta Baixa Fluxo de Circulação Geral (Fonte: autoras, 2014)

A figura 14, representa prováveis pontos dos possíveis deslocamentos em vermelho indicando o péssimo fluxo de circulação entre os postos de trabalho, na cor verde indicam boa circulação e na cor amarelo requerem atenção. Merece destaque a circulação em vermelho situada dentro da Estante Modular, onde se faz necessário ainda o uso de uma pequena escada para facilitar o arquivamento/desarquivamento das pastas funcionais situadas nas prateleiras mais altas, forçando o trabalhador adotar posturas inadequadas para a realização da tarefa, configurando-se um ponto de risco à saúde do trabalhador. No corredor externo, encontram-se armazenadas, por falta de espaço adequado, várias caixas com material de escritório para uso na Divisão, dificultando o fluxo de circulação.

\subsection{Etapa 05 - Percepção Ambiental do Usuário:}

De acordo com Villarouco (2008), um ponto importante da avaliação do ambiente construído é a percepção do usuário, pois este é o elemento que mais sofre com todas as 


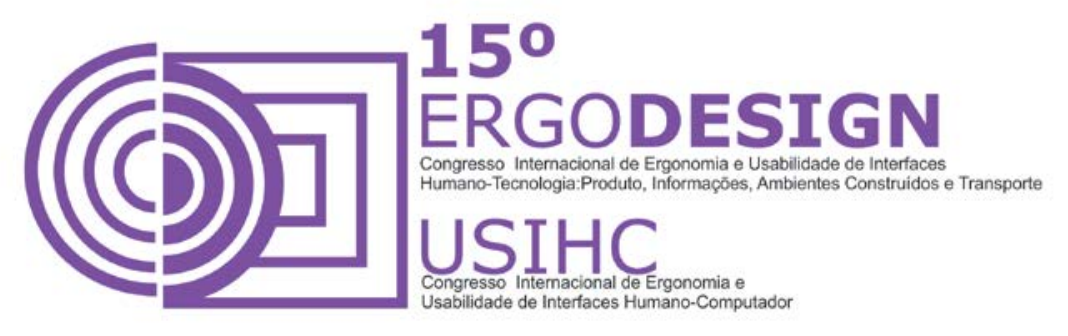

sensações que o ambiente pode gerar. Assim, foi aplicada a Constelação de Atributos, ferramenta idealizada por Moles em 1968 e permite a compreensão da consciência psicológica do usuário frente ao espaço que ocupa. Esta representação gráfica é composta por um núcleo que representa o objeto de estudo e por "estrelas" que representam os atributos especiais. A distância entre o atributo e o núcleo, chamada de distância psicológica, determina o grau de importância de cada atributo, além de auxiliar no conhecimento da percepção do usuário em relação ao ambiente (VASCONCELOS; VILLAROUCO;SOARES,2009). Para a construção do gráfico da Constelação de Atributos foram realizadas duas perguntas, mencionadas no início deste estudo, propiciando a análise de duas esferas do ambiente construído: uma para a conceituação do Arquivo Funcional Imaginário, com associação de ideias voltadas para as características espontâneas, e outra que define o Arquivo Funcional Real, com associação de ideias a partir de características induzidas.

A figura 15 foi avaliada a imagem simbólica do indivíduo frente ao ambiente, identificada como Arquivo Funcional Imaginário, através da seguinte pergunta: Quando você pensa em um "Arquivo Funcional" que ideias ou imagens vem à mente? As respostas foram categorizadas e agrupadas em quatro categorias: conforto do ambiente; percepção; equipamento T.I. e Organização Documental.

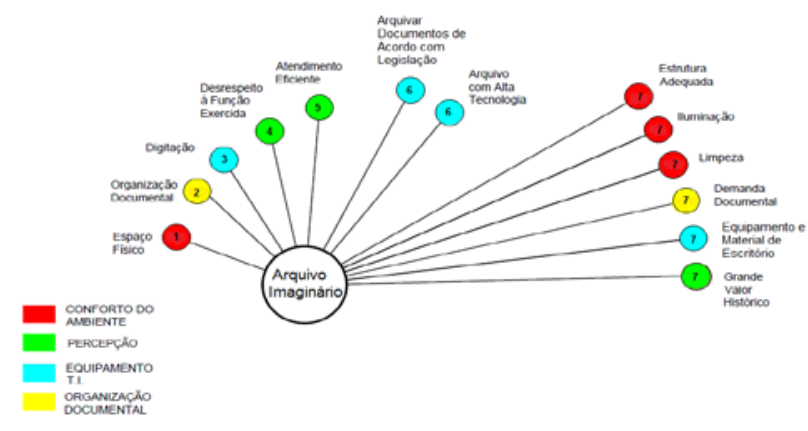

Figura 15 - Constelação de Atributos / Arquivo Imaginário. (Fonte: autoras, 2014)

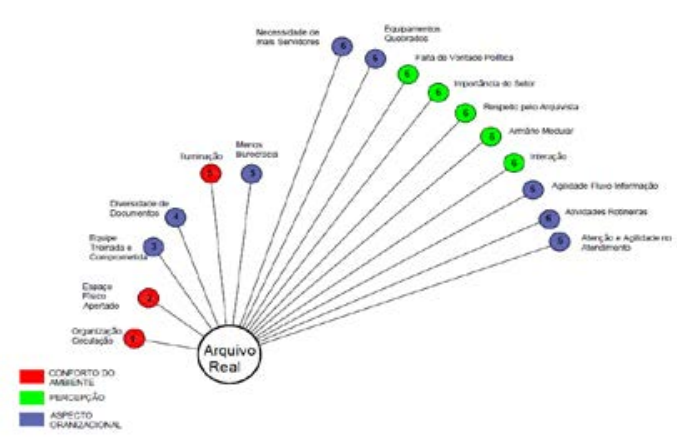

Figura 16 - Constelação de Atributos / Arquivo Real (Fonte: autoras, 2014)

$\mathrm{Na}$ Constelação de Atributos para o Arquivo Imaginário, o conforto ambiental apareceu como atributo mais referenciado, no qual o espaço físico surge em primeiro lugar, seguido da percepção apresentada pelos usuários que tornam latente os anseios dos mesmos para o ambiente imaginário. Com relação aos Equipamentos/Tecnologia da Informação, tornou-se evidente o desejo de se utilizar de equipamentos mais modernos para tornar o serviço mais eficiente. Já na categoria de Organização documental demostra o grande volume de trabalho e também a necessidade de agilizar as rotinas de trabalho inerentes ao Arquivamento. A figura 16, foi avaliada a imagem real do indivíduo frente ao ambiente, identificada como Arquivo Funcional Ideal, através da seguinte pergunta: Quando você pensa neste "Arquivo Funcional" 


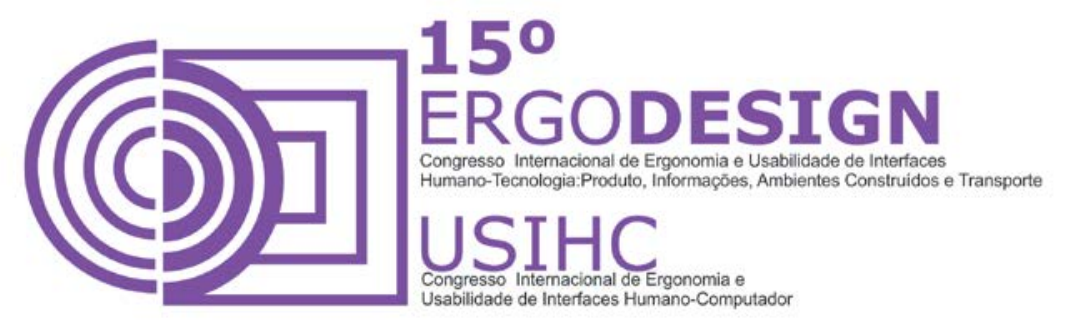

que ideias ou imagens vem à mente? As respostas foram categorizadas e agrupadas em três categorias: conforto do ambiente; percepção e Aspecto Organizacional. Na Constelação de Atributos para o Arquivo Real, percebeu-se a predominância negativa para a categoria do conforto ambiental, indicando o desejo por um espaço físico adequado as atividades do Setor. A percepção apresentada surge em seguida e evidenciam aspectos também pela necessidade de respeito pela atividade do Arquivista. Com relação aos Aspetos Organizacionais, tornouse evidente que uma melhor organização do trabalho de modo a agilizar o serviço prestado, tornando-o menos burocrático, faz-se necessário.

\subsection{Etapa 05 - Diagnóstico Ergonômico do Ambiente e Recomendações:}

De modo geral, com intuito de eliminar ou diminuir os problemas identificados, e portanto melhorar o desenvolvimento das atividades e a satisfação do usuário, construiu-se, a partir dos problemas identificados pela percepção dos pesquisadores, além dos dados levantados pelas entrevistas e questionários, o quadro 4:

\begin{tabular}{|c|l|}
\hline \multicolumn{2}{|c|}{ ACHADOS DA AVALIAÇÃO ERGONÔMICA DO AMBIENTE CONSTRUÍDO } \\
\hline PROBLEMAS & \multicolumn{1}{c|}{ RECONEMDAÇÕES } \\
\hline Infraestrutura & $\begin{array}{l}\text { Ampliação do espaço físico da Divisão do Arquivo Funcional IES; Criação de um Laboratório } \\
\text { de higienização documental; Reorganização do layout (bancadas e mobiliário em geral). }\end{array}$ \\
\hline Limpeza inadequada & Treinamento específico à equipe que realiza a limpeza no ambiente de Arquivo. \\
\hline Conforto Lumínico & Projeto específico criado por profissional habilitado para lluminância da Divisão. \\
\hline $\begin{array}{c}\text { Risco Biológico } \\
\text { (fungos e bactérias) }\end{array}$ & $\begin{array}{l}\text { Uso dos IPI's e a partir da Criação do Laboratório de Higienização de documentos promover } \\
\text { uma melhor reorganização dos espaços. }\end{array}$ \\
\hline
\end{tabular}

Quadro 04 - Problemas Identificados e proposições de Recomendações. (Fonte: autoras, 2014)

Desta forma, a partir da pesquisa realizada, conseguiu-se avaliar o ambiente construído do Arquivo Funcional de uma IES e implantando-se as recomendações sugeridas, espera-se "reduzir a fadiga, estresse, erros e acidentes, proporcionando segurança, satisfação e saúde dos trabalhadores, durante seu relacionamento com o sistema produtivo" (IIDA, 2005, p.9).

\section{CONCLUSÃO}

Organizar documentos significa zelar pela história, informação e conhecimento. Quando existe preocupação em gerenciar o material acumulado, o arquivo passa a exercer um importante papel no dia-a-dia administrativo, favorecendo uma melhor prestação de serviços à comunidade, pois um arquivo é a memória viva da Instituição!

\section{REFERÊNCIAS}

ASSOCIAÇÃO BRASILEIRA DE NORMAS TÉCNICAS. NBR 9050: Acessibilidade a Edificações, Mobiliário, Espaços e Equipamentos Urbanos. Rio de Janeiro, 2004.

ASSOCIAÇÃO BRASILEIRA DE NORMAS TÉCNICAS. NBR 15.413: Iluminância de Interiores. Rio de Janeiro. 1987. 


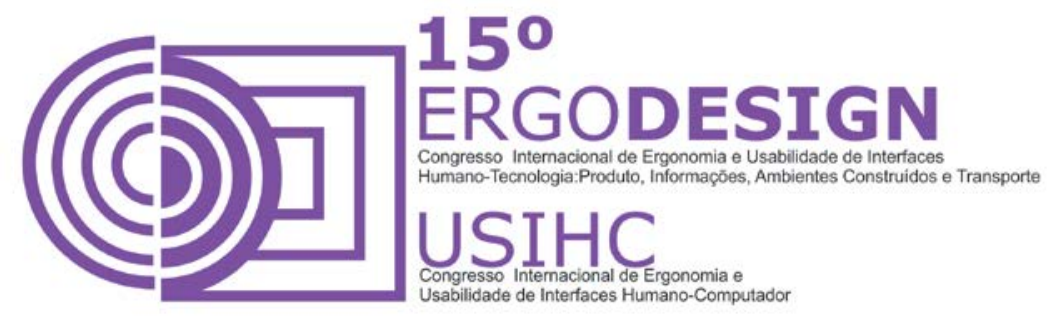

ASSOCIAÇÃO BRASILEIRA DE NORMAS TÉCNICAS. NBR 10.152: Níveis de Ruído para Conforto Acústico. Rio de Janeiro, 1987.

BERVIAN, P. A.; SILVA, R. da. Medologia Científica. 6º Ed. São Paulo: Pearson Prentice Hall, 2007.

BRASIL. Ministério do Trabalho e Emprego. NR 17 - Ergonomia. Brasília: 2007.CERVO, A. L.;

http://www.artigos.com/artigos/tutoriais/o-que-e-um-arquivo?-343/artigo/\#.VGaV6abXoxA

IIDA, Itiro. Ergonomia: projeto e produção. São Paulo. Edgar Blucher. 2005.

MONT`ÀLVÃO, C. A ergonomia do ambiente construido no Brasil. In: MONT`ALVÃO, C.; VILLAROUCO, V.(org) Um novo olhar para o projeto: a ergonomia no ambiente construido. Rio de Janeiro: 2AB, 2011.

UNIVERSIDADE FEDERAL DE PERNAMBUCO. Disponível em http://www.ufpe.br Acesso em dezembro de 2014.

VASCONCELOS, Christinane F.; VILLAROUCO, Vilma; SOARES, Marcelo M. Avaliação ergonômica do ambiente construído: estudo de caso de uma biblioteca universitária. Ação ergonômica, v.4. p. 5-25, 2009.

VILLAROUCO, Vilma. Construindo uma Metodologia de Avaliação Ergonômica do Ambiente. AVEA. 2014. Congresso Brasileiro de Ergonomia. Porto Alegre. Anais ABERGO. 